\title{
A Dynamic Knowledge Models of Nitrogen Fertilizer and Computer System for Cotton
}

\author{
ChunJing Si \\ College of Information Engineering, Tarim University, Xinjiang 843300, China \\ smallx1002@sina.com
}

\begin{abstract}
Through analyzing the newest research results about nitrogen management of cotton and experimental results, and on the basis of the different effects of cotton yield, plant height and leaf area, a dynamic knowledge model for decision making on total nitrogen and their distribution among main growth stages of cotton under different environments and yield targets was developed with the principles of nitrogen balance and by integrating the factors of climate, soil, yield and so on. A comprehensive and intelligent computer system for cotton management was established using VC++6.0 and SQL Server 2003.
\end{abstract}

Keywords: nitrogen management, influence factors, dynamic knowledge models, decision support system.

\section{Introduction}

As nitrogen is one of the important components of protein, which is also the important element making up of cellular plasm, so to speak, life activities cannot be formed without nitrogen. The nutrition level of nitrogen fertilizer has a very essential influence on cottons' growth and development, which not only limits the height of cotton leaves, but also cotton yields. In the case of lacking the nitrogen fertilizer, cottons take on a slow and weak growth, with undersized and thin stems, cotton buds and bolls with a high expulsion rate and rare bolls; in the case of using too much or improperly fertilizing in different growth periods of cottons, sugars formed by organic nutrition consume too much with little accumulation, excessive vegetative growth and increasing expulsion. Fertilization of abundant nitrogen fertilizers will not only decrease the utilization rate of fertilizer and increase its cost, but also cause adverse effects to the environment. Different treatments of nitrogen fertilizer have certain influence on the growth of cotton organs and the yields. So, it will be of much importance for guiding the agricultural production to create accurate and effective nitrogen management models and design and develop them into systems.

\section{Materials and Methods}

\subsection{Experiment Design}

The experiment is conducted in agricultural experiment station (with latitude of $40^{\circ} 32^{\prime}$ $\mathrm{N}$ and longitude of $81^{\circ} 18^{\prime} \mathrm{E}$ ) of Tarim University in Xinjiang Province in April, 2011.

D. Li and Y. Chen (Eds.): CCTA 2013, Part I, IFIP AICT 419, pp. 52-60, 2014.

(C) IFIP International Federation for Information Processing 2014 
With a height above the sea level of 900-950 meters and of warm temperate desert climate, the experimental zone locates in the upper and middle reaches of Tarim River, graced with rich resources of water and soil, dry weather, abundant sunlight and four distinctive seasons. For nearly 30 years, the area has an average annual precipitation of 40.1-82.5 mm, with little rain in summer and little snow in winter, an average annual temperature of $10.7^{\circ} \mathrm{C}$ and a total annual sunshine duration of 2900 hours, suitable for the growth of long-staple cotton. The cottons are planted by means of plot, with a planting density of 12200 plants per mu. The experimental soil is loam, with $14 \mathrm{~g} / \mathrm{kg}$ organic content, $0.5 \mathrm{~g} / \mathrm{kg}$ total nitrogen, $85 \mathrm{mg} / \mathrm{kg}$ effective nitrogen, $14 \mathrm{mg} / \mathrm{kg}$ available phosphorus and $75 \mathrm{mg} / \mathrm{kg}$ rapidly available potassium. The experimental variety is the New Sea 21 of long-staple cotton, with a plot area of $132 \mathrm{~m}^{2}$.

This experiment designs five nitrogen fertilization treatments, namely, 0, 180, 240, $300,360 \mathrm{~kg} / \mathrm{hm}^{2}$, with the amount of base fertilizer holding $45 \%$ of the total fertilization amount, and the remainder being top dressing/nitrogen application, respectively in the periods from the bud period to the flower and boll stage and 3 fertilization proportions with water of $15 \%, 25 \%$ and $15 \%$. Besides, the phosphorus and potassium fertilizers in the base fertilizer separately are $\mathrm{P}_{2} \mathrm{O}_{5} 138 \mathrm{~kg} / \mathrm{hm}^{2}$ and $\mathrm{K}_{2} \mathrm{O} 72 \mathrm{~kg} / \mathrm{hm}^{2}$. The experiment is arranged in random groups, with 3 repeated treatments in each group. The samples make up of the following table 1 :

Table 1. Schemes of every fertilization treatment in the experiment

\begin{tabular}{cccccccccc}
\hline \multirow{2}{*}{ Treatment } & \multicolumn{3}{c}{ Total amount } & \multicolumn{3}{c}{ Base fertilizer } & \multicolumn{2}{c}{ Topdressing nitrogen fertilizer } \\
& $\mathrm{N}$ & $\mathrm{P}_{2} \mathrm{O}_{5}$ & $\mathrm{~K}_{2} \mathrm{O}$ & $\mathrm{N}$ & $\mathrm{P}_{2} \mathrm{O}_{5}$ & $\mathrm{~K}_{2} \mathrm{O}$ & $1^{\text {st }}(6.10)$ & $2^{\text {nd }}(7.15)$ & $3^{\text {rd }}(8.20)$ \\
\hline $\mathrm{N} 0$ & 0 & 138 & 72 & 0 & 138 & 72 & 0 & 0 & 0 \\
$\mathrm{~N} 1$ & 180 & 138 & 72 & 81 & 138 & 72 & 27 & 45 & 27 \\
$\mathrm{~N} 2$ & 240 & 138 & 72 & 108 & 138 & 72 & 36 & 60 & 36 \\
$\mathrm{~N} 3$ & 300 & 138 & 72 & 135 & 138 & 72 & 45 & 75 & 45 \\
$\mathrm{~N} 4$ & 360 & 138 & 72 & 162 & 138 & 72 & 54 & 90 & 54 \\
\hline
\end{tabular}

\subsection{Experimental Method}

In the main growth period, seedling stage, bud stage, flower and boll stage and boll period, samples are respectively taken in the time between 10:00-12:00 am on the corresponding dates. Each nitrogen fertilizer treatment area randomly selects 3 representative cotton plants ( 5 plants in the bud period), and measures related data from the selected plant samples.

The plant height of cotton: the plant heights of cotton are measured with rulers on June $9^{\text {th }}$, June $17^{\text {th }}$, July $2^{\text {nd }}$, July $17^{\text {th }}$ and September $15^{\text {th }}$.

The length and width of cotton leaves: the length and width of the largest leaves in representative plants are measured with rulers on June $9^{\text {th }}$, June $17^{\text {th }}$, July $2^{\text {nd }}$, July $17^{\text {th }}$ and September $15^{\text {th }}$.

The leaf area: according to the quantitative functional relationship between pulse length and leaf area in cotton leaves applied in Literature [2], the leaf area is solved. With the pulse length $\mathrm{x}$ as the independent variable and the leaf area $\mathrm{y}$ as the dependent variable, the quadratic regression equation of one variable $=2.4337-0.4328 x+0.8265 x^{2}$ is established. 


\section{The Influence of Nitrogen Fertilizer on the Growth of Long-Staple Cotton}

\subsection{The Influence of Nitrogen Fertilizer on the Yield of Long-Staple Cotton}

The research literature [3-5] show there is certain quantitative relationship existing between nitrogen fertilizer NR and the target of yield TY $(\mathrm{kg} / \mathrm{ha})$, which can be expressed in the following linear function:

$$
N R=0.1062 \times T Y+17.181 \quad R=0.8313^{* *}
$$

The literature [6] proves that under the condition of border irrigation in southern Xinjiang area, different amounts of nitrogen fertilization have influences on the boll number of each cotton plant, the weight of each boll and the yield of seed cottons. This research suggests that under different nitrogen treatments, there is certain difference in the boll number of each cotton plant, the weight of each boll and the yield of seed cotton. Thereinto, the relationship of the boll number of each cotton plant and nitrogen treatments accords with quadratic curve equation. At first, the yield of seed cotton increases with the increasing amount of nitrogen fertilization, but when the nitrogen level reaches $\mathrm{N} 3$, the yield takes on downtrend. By simulating and matching the nitrogen fertilizer effect of cottons with quadratic equation of one variable, the experimenter concludes the correlation between the amount of nitrogen fertilization and the cotton yield as follows:

$$
y=-0.0039 x^{2}+2.6895 x+1962.9 \quad R^{2}=0.9576^{* *}
$$

In the equation, $\mathrm{y}$ refers to the yield and $\mathrm{x}$ the amount of nitrogen fertilization.

Table 2. The influence of different amounts of nitrogen fertilizer on cotton yields

\begin{tabular}{cccc}
\hline Treatment & $\begin{array}{c}\text { Boll numbers of } \\
\text { each plant(No./plant) }\end{array}$ & $\begin{array}{c}\text { Weight of each } \\
\text { plant(g) }\end{array}$ & $\begin{array}{c}\text { Yield of seed } \\
\left.\text { cotton(kg.//m }{ }^{2}\right)\end{array}$ \\
\hline N0 & 7.6 & 2.9 & 4562.2 \\
N1 & 8.3 & 2.8 & 4810.7 \\
N2 & 8.4 & 2.9 & 5042.5 \\
N3 & 8.5 & 3.1 & 5454.5 \\
N4 & 8.4 & 3.0 & 5216.4 \\
\hline
\end{tabular}

\subsection{The Influence of Nitrogen Fertilizer on Plant Height and Leaf Area of the Long-Staple Cotton}

The experimental result (seen in Chart 3) shows that with the advancement of long-staple cotton's growth process, there is no difference in different nitrogen fertilizer treatments in periods of seedling and bud, that the growth processes of cotton in the beginning of flowering and at full-blossom stage are both a little delayed and that in the full-blossom stage, the heights of front plants rapidly increase and after that, the difference in plant height with different nitrogen treatments gradually increases with the growth process. 
Table 3. The influence of different nitrogen levels on plant height, leaf number and leaf area

\begin{tabular}{ccccccc}
\hline Treatment & $\begin{array}{c}\text { Plant } \\
\text { height(cm) }\end{array}$ & $\begin{array}{c}\text { True leaf } \\
\text { number(leaf } \\
\text { number/plant) } \\
\text { (Stage of 4 leaves) May 21th }\end{array}$ & $\begin{array}{c}\text { Leaf } \\
\left(\mathrm{cm}^{2} / \text { plant) }\right.\end{array}$ & $\begin{array}{c}\text { Plant } \\
\text { height }(\mathrm{cm})\end{array}$ & $\begin{array}{c}\text { True leaf } \\
\text { number(leaf } \\
\text { number/plant) } \\
\text { (Stage of 5 leaves) May 21th }\end{array}$ & $\begin{array}{c}\text { Leaf area } \\
\left(\mathrm{cm}^{2} / \text { plant) }\right.\end{array}$ \\
\hline N0 & 4.0 & 3.5 & 61.2 & 5.1 & 4.8 & 109.8 \\
N1 & 4.1 & 3.6 & 64.3 & 5.6 & 5.0 & 118.5 \\
N2 & 4.3 & 3.8 & 84.5 & 6.1 & 5.0 & 133.0 \\
N3 & 3.1 & 3.5 & 59.8 & 5.7 & 5.1 & 122.3 \\
N4 & 3.6 & 3.5 & 55.7 & 5.4 & 5.0 & 114.5 \\
\hline
\end{tabular}

\section{The Dynamic Knowledge Model of Nitrogen Management}

\subsection{The Establishment of the Model/the Modeling}

Based on the widely collecting and consulting the latest literatures about the cultivation, the soil science and plant nutrition of the long-staple cotton, by means of the principle of system analysis and mathematical modeling method, the experiment builds the relevant quantitative mathematical model of nitrogen management and develops the cotton nitrogen management system based on dynamic knowledge model, and finally tests the correctness of this model with practical applications and optimizes the model with understanding and analyzing the feedback information from the system.

\subsection{Descriptions of Model Algorithm}

\subsubsection{The Amount of Soil Nitrogen Supply in Season}

The amount of soil nitrogen supply in season: $S N=O N+I O N$

In the equation, $\mathrm{ON}$ refers to the supply amount of reducible $\mathrm{N}$ element in season and ION the supply amount of irreducible $\mathrm{N}$ element in season.

(1). the supply amount of reducible $\mathrm{N}$ element in season

$$
O N=\frac{0.08 \times T S N \times S P D \times S B W \times N(t) \times S N U E}{365} \times 1000
$$

In the equation, TSN refers to the real total amount of $\mathrm{N}$ element in the soil $\left(\mathrm{g}_{\mathrm{kg}} \mathrm{kg}^{-1}\right)$; SPD the thickness of the top layer $(\mathrm{cm})$; SBW the volume $\left(\mathrm{g} \cdot \mathrm{kg}^{-1}\right)$. The utilization rate of the fertilizer in season is affected by the fertilizer variety, fertilizing method, weather conditions and soil environment and so on. Under the conventional fertilizing technique, the utilization rate of fertilizer in season is generally $32.5 \% \pm 2.5 \%$. Recently, as a new fertilizing technique, drip fertigation has obtained/achieved much development. Because the fertilizer is quantitatively applied with water, the solubleness of the fertilizer and the close fertilization are increased, thus improving the fertilizer efficiency and the utilization rate of nitrogen fertilizer reaches $50.5 \% \pm 3.5 \%$. According to the fertilization pattern and past experience, users can determine the utilization rate of corresponding fertilizers in season. 
$\mathrm{N}(\mathrm{t})$ refers to the total number of standardized days under water temperature effect:

$$
N(t)=N(t)_{1}^{\prime}+N(t)_{2}^{\prime}+\cdots+N(t)_{365}^{\prime}
$$

$\mathrm{N}$ (t) I refers to the number of standardized days under the effect of water and the temperature of Number i, whose value is:

If the value of $P D T_{i}$ (psychological development time the variety accumulates gradually under actual sowing dates) is taken and fixed from 0 to 144 , then

$$
N(t)_{i}^{\prime}=F_{T}(t) \times F_{w}(t)
$$

Otherwise, its value is 0 .

FT (t) is the influence function of temperature to nitrogen fertilization, whose value is $F_{T}(t)=\left(8 \times e^{-0.058 \times S T A_{20}}\right)^{\frac{S T A_{20}-30}{10}}$. Thereinto, STA20 is the soil temperature when the plough layer is $20 \mathrm{~cm}$ thick.

$\mathrm{FW}(\mathrm{t})$ is the influence function of moisture to nitrogen fertilization.

$$
F_{w}(t)=\left\{\begin{array}{cc}
0.2 & W(t) \leq W_{D} \\
0.2+0.8 \times \frac{W(t)-W_{D}}{W_{O}-W_{D}} & W(t) \leq W_{O} \\
1-0.6 \times \frac{W(t)-W_{O}}{W_{S}-W_{O}} & W(t) \leq W_{S} \\
0 & W(t)>W_{S}
\end{array}\right.
$$

WD is the wilting moisture content; WO the optimum soil moisture content under mineralization; Ws saturated moisture content of soil; $\mathrm{W}(\mathrm{t})$ the actual moisture content of soil.

(2). The supply amount of irreducible $\mathrm{N}$ element in season

$$
I O N=A O V N \times S P D \times S B W \times 10
$$

In the equation, $\mathrm{AOVN}$ is the content of irreducible $\mathrm{N}$ element and effective nitrogen in the top layer of soil; SPD the thickness of the topsoil (cm); SBW soil capacity $\left(\mathrm{g} \cdot \mathrm{kg}^{-1}\right)$.

\subsubsection{The Necessary/Needed Amount of $\mathbf{N}$ under Specific Yields}

The necessary amount of $\mathrm{N}$ under specific yields URN $\left(\mathrm{kg} \cdot \mathrm{hm}^{-2}\right)$

$$
U R_{N}=\frac{418.5966}{1+e^{-0.0004 \times(T Y-4151.962)}}
$$

In the equation, TY $\left(\mathrm{kg} / \mathrm{hm}^{2}\right)$ is used to calculate the realizable yield potential of users.

$$
T Y=\left\{\begin{array}{cl}
T Y_{\max } & Y M \times\left(1+\frac{Y L P P-Y M}{4 \times Y L P P}\right) \geq T Y_{\max } \\
Y M \times\left(1+\frac{Y L P P-Y M}{4 \times Y L P P}\right) & Y M \times\left(1+\frac{Y L P P-Y M}{4 \times Y L P P}\right)<T Y_{\max }
\end{array}\right.
$$


In the equation, TYmax is the yield potential under the earliest time of suitable sowing period; YM the average yield in the first three years; YLPP the production potential of production technology.

\subsubsection{The Fertilizing Ratio of Organic $N$ to Inorganic N OINR1: OINR2}

(1) The fertilization amount of organic $\mathrm{N}$

$$
O I N R_{1}=\left\{\begin{array}{lc}
5-\left(1-2.5 / L A^{\prime}\right)-\left(1-1.5 \times T Y / T Y_{\max }\right) & O M C<8 \\
4-\left(1-2.5 / L A^{\prime}\right)-\left(1-1.5 \times T Y / T Y_{\max }\right) & 8 \leq O M C<14 \\
3-\left(1-2.5 / L A^{\prime}\right)-\left(1-1.5 \times T Y / T Y_{\max }\right) & O M C \geq 14
\end{array}\right.
$$

In the equation, TY $\left(\mathrm{kg} / \mathrm{hm}^{2}\right)$ is used to calculate the realizable yield potential of users; TYmax is the yield potential under the earliest time of suitable sowing period; OMC the organic material content in the soil $(\mathrm{g} / \mathrm{kg})$.

LA is the age of transplanted leaves after PS correcting the seeding method, whose value is:

$$
L A^{\prime}=\left\{\begin{array}{cc}
2.5 & \text { direct seeding } \\
L A & \text { Otherwise }
\end{array},\right. \text { LA refers to the age of transplanted leaves }
$$

(2) The fertilization amount of inorganic $\mathrm{N} \mathrm{OINR}_{2}$

$\mathrm{OINR}_{2} 10-\mathrm{OINR}_{1}$

\subsubsection{The Drip Fertigation}

In different growth stages of cotton, the ratio of base fertilizer to top-dressing; the drip fertigation ratio in base fertilizer, bud stage, the beginning of flowering, the full-blossom stage, boll stage and early flocculant stage, namely, BTRND1: BTRND2: BTRND3 : BTRND4 : BTRND5 : BTRND6.

(1) The base fertilizer

$$
B T R N_{D 1}=\left\{\begin{array}{cc}
4.5-\left(1-2.5 / L A^{\prime}\right)+C L A Y C / 100+\left(1-1.5 \times T Y / T Y_{\max }\right) & T Y \leq 0.4 \times T Y_{\max } \\
3.5-\left(1-2.5 / L A^{\prime}\right)+C L A Y C / 100+\left(1-1.5 \times T Y / T Y_{\max }\right) & 0.4 \times T Y_{\max }<T Y \leq 0.7 \times T Y_{\max } \\
2.5-\left(1-2.5 / L A^{\prime}\right)+C L A Y C / 100+\left(1-1.5 \times T Y / T Y_{\max }\right) & T Y>0.7 \times T Y_{\max }
\end{array}\right.
$$

In the equation, LA is the age of transplanted leaves after PS correcting the seeding method; TY $\left(\mathrm{kg} / \mathrm{hm}^{2}\right)$ is used to calculate the realizable yield potential of users; TYmax is the yield potential under the earliest time of suitable sowing period.

CLAYC is the content of the physical clay (\%), whose value is listed in Chart 4 as follows: 
Table 4. The soil texture and the corresponding values of CLAYC

\begin{tabular}{cc}
\hline Soil texture & CLAYC value \\
\hline Sandy soil & 7.5 \\
Sandy loam & 15 \\
Light loam & 25 \\
Middle loam & 37.5 \\
Heavy loam & 52.5 \\
Clay & 65 \\
\hline
\end{tabular}

(2) The bud stage

$$
B_{T R N_{D 2}}=\left\{\begin{array}{cl}
1 & T Y \leq 0.4 \times T Y_{\max } \\
0.9 & T Y>0.4 \times T Y_{\max }
\end{array}\right.
$$

$\mathrm{TY}\left(\mathrm{kg} / \mathrm{hm}^{2}\right)$ is used to calculate the realizable yield potential of users; TYmax is the yield potential under the earliest time of suitable sowing period.

(3) The beginning of flowering stage

$$
B T R N_{D 3}=\left\{\begin{array}{cc}
2.2+\left(1-2.5 / L A^{\prime}\right)-C L A Y C / 100-\left(1-1.5 \times T Y / T Y_{\max }\right) & T Y \leq 0.4 \times T Y_{\text {max }} \\
2+\left(1-2.5 / L A^{\prime}\right)-C L A Y C / 100-\left(1-1.5 \times T Y / T Y_{\text {max }}\right) & 0.4 \times T Y_{\text {max }}<T Y \leq 0.7 \times T Y_{\max } \\
1.8+\left(1-2.5 / L A^{\prime}\right)-C L A Y C / 100-\left(1-1.5 \times T Y / T Y_{\max }\right) & T Y>0.7 \times T Y_{\text {max }}
\end{array}\right.
$$

(4) The full-blossom stage

$$
B T R N_{D 4}=\left\{\begin{array}{cc}
2-\left(1-2.5 / L A^{\prime}\right)+C L A Y C / 100-\left(1-1.5 \times T Y / T Y_{\max }\right) & T Y \leq 0.4 \times T Y_{\max } \\
2.5-\left(1-2.5 / L A^{\prime}\right)+C L A Y C / 100-\left(1-1.5 \times T Y / T Y_{\max }\right) & 0.4 \times T Y_{\max }<T Y \leq 0.7 \times T Y_{\max } \\
3-\left(1-2.5 / L A^{\prime}\right)+C L A Y C / 100-\left(1-1.5 \times T Y / T Y_{\max }\right) & T Y>0.7 \times T Y_{\max }
\end{array}\right.
$$

(5) The boll stage

$$
B T R N_{D 5}=\left\{\begin{array}{cc}
0.3+\left(1-2.5 / L A^{\prime}\right)-C L A Y C / 100+\left(1-1.5 \times T Y / T Y_{\max }\right) & T Y \leq 0.4 \times T Y_{\max } \\
0.8+\left(1-2.5 / L A^{\prime}\right)-C L A Y C / 100+\left(1-1.5 \times T Y / T Y_{\max }\right) & 0.4 \times T Y_{\max }<T Y \leq 0.7 \times T Y_{\max } \\
1.4+\left(1-2.5 / L A^{\prime}\right)-C L A Y C / 100+\left(1-1.5 \times T Y / T Y_{\max }\right) & T Y>0.7 \times T Y_{\max }
\end{array}\right.
$$

(6) The early flocculant stage

$$
B T R N_{D 6}=\left\{\begin{array}{cc}
0 & T Y \leq 0.4 \times T Y_{\max } \\
0.3 & 0.4 \times T Y_{\max }<T Y \leq 0.7 \times T Y_{\max } \\
0.4 & T Y>0.7 \times T Y_{\max }
\end{array}\right.
$$

\subsection{Verification of the Model}

By systemically using the meteorological data, soil bank, commercial variety, perennial production data of 5 areas with different latitudes like Alear City, Bachu, Bytown, and Shihezi, the experimenter designs management schemes of cotton nitrogen in normal 
years for these areas and then compares with the cotton cultivation mode in local use to find that they are basically consistent, which suggests this system is of good practicality and accuracy.

\section{The Design and Development of Nitrogen Management System}

By understanding and refining document literatures and expert knowledge, combining with field trials and dynamic knowledge model of nitrogen management, with the help of programming language $\mathrm{VC}++6.0$ and data platform SQL 2000, the experiment designs and develops nitrogen management system based on dynamic knowledge model, which mainly covers 4 modules.

The first three modules simulate the influences of different nitrogen treatments on such parameters as the yield of long-staple cotton, the plant height and leaves. Thereinto, the module of production estimation realizes the influences of 5 nitrogen treatments on the number of bolls in each cotton plant, the weight of each boll and the seed cotton yield, further realizing the estimation of long-staple cotton yield; by analyzing the influences of 5 nitrogen treatments on long-staple plants, the module of plant height prediction concludes to predict the plant height by the fertilization amount of nitrogen fertilizer; by the influences of 5 nitrogen treatments on leaf number and leaf area, the leaf parameter estimation module concludes to estimate related parameters of leaves according to the fertilization amount of nitrogen fertilizer.

According to input parameters by users, nitrogen management module can help users calculate the amount of soil nitrogen supply in season, the necessary amount of nitrogen under specific yields, and the fertilization proportion of long-staple cotton in different growth stages under drip fertigation.

\section{Conclusion}

By understanding and refining document literatures and expert knowledge, combining with field trials, the study analyzes the influences of nitrogen fertilizer on relevant parameters such as the cotton yield, plant height and leaves, further giving out the dynamic knowledge model of nitrogen management and designs and develops the cotton nitrogen management system based on dynamic knowledge model. Proved by practical applications, dynamic knowledge model is of good practicality and accuracy, and the system is characterized by fast and convenient uses, practicality and universality. In the future studies, the system will strengthen the study on the influence of nitrogen fertilizer on other cotton organs and be able to make better service for production.

\section{References}

1. Xue, X., Chen, B., Zhou, Z.: The Influence of Cultivation Pattern on Cottons' Growth. Cotton Science 19(6), 440-445 (2009)

2. Li, X., Chen, Y.: The Quick Calculation of the Long-staple Cotton Leaf Area by Look-up Table. Xinjiang Agricultural Sciences (4), 154-155 (1993) 
3. Research Institute of Chinese Academy of Agricultural Sciences. Chinese Cotton Cultivation, pp. 449-501. Shanghai Science and Technology Press, Shanghai (1983)

4. Li, J., Liu, R.: Cotton Nutrition Fertilization and Diagnosis, pp. 64-97. China's Agricultural Science and Technology Press, Beijing (1992)

5. Mao, S.: Cotton Nutrition and Fertilization, pp. 13-44. China's Agricultural Science and Technology Press, Beijing (1993)

6. Wang, X., Zhang, Y.: Diagnostic Study on Nitrogen Nutrition Status in Cottons. Plant Nutrition and Fertilizer Science 12(5), 656-661 (2006)

7. Wang, J., Gao, S., Chen, L., Ma, F.: The Dynamic Knowledge Model of the Management of Processing Tomato Fertilizer. Chinese Journal of Eco-agriculture 19(2), 285-292 (2011)

8. Mao, D., Chen, L., Zhang, C., Luo, M.: The Study on Crop Fertilization Model and System in Quzhou. Journal of Chinese Agricultural University 8, 53-56 (2003) 